\title{
AGRICULTURA FAMILIAR: UM ESTUDO SOBRE A JUVENTUDE RURAL NO MUNICÍPIO DE SERRA DO MEL - RN.
}

\author{
Paulo Segundo e Silva \\ AACC - Associação de Apoio às Comunidades do Campo - Natal/RN \\ E-mail:Paulo@aacc.org.br \\ Edimar Teixeira Diniz Filho \\ SEAPAC - Serviço de Apoio aos Projetos Alternativos Comunitários - Mossoró - RN \\ E-mail: edimar_diniz@mikrocenter.com.br \\ Vívian Patrícia Borba Borges Maracajá \\ FACISA - Faculdade de Ciências Sociais Aplicadas - Campina Grande - PB \\ E-mail binhav@ig.com.br \\ Patrício Borges Maracaja \\ Departamento de Ciência Vegetais - UFERSA - Universidade Federal Rural do Semi-Árido \\ E-mail:patrício@ufersa.edu.br \\ Tadeu Fladiner Costa Pereira \\ Departamento de Ciência Vegetais - UFERSA - Universidade Federal Rural do Semi-Árido \\ E-mail: fladner@gmail.com
}

\begin{abstract}
RESUMO - Com o objetivo de fazer um estudo sobre a juventude rural dentro do contexto de transformações por que vem passando agricultura familiar, foram entrevistados pais, filhos e filhas de agricultores. Com o intuito de caracterizar os jovens, levando em consideração aspectos de sua vida cotidiana, educação, sua ocupação dentro e fora do lote, sua renda, relações de gênero e seus anseios em relação ao futuro. Foi aplicado um questionário junto aos pais e outro aos jovens com idade entre 15 e 25 anos, nas vilas agrícolas Amazonas e Pará, no município de Serra do Mel, estado do Rio Grande do Norte. Pôde-se constatar que nas localidades existem muitas dificuldades em relação ao acesso e qualidade da escola/educação, os jovens não querem permanecer na zona rural, falta de renda, as jovens recebem menos, mesmo exercendo a mesma atividade que os jovens e a completa falta de espaços para lazer nessas vilas. O campo é apontado como um lugar bom para se viver, mas não oferece condições para o jovem permanecer morando nele.
\end{abstract}

Palavras chave: Agricultura familiar, juventude, relações de gênero.

\section{FAMILIAR AGRICULTURE: A STUDY ABOUT AGRICULTURAL YOUTH IN SERRA DO MEL CITY - RN}

ABSTRACT - With the objective of make a study about the agricultural youth in the context of the transformations that the familiar agriculture is facing, were interviewed parents, sons and daughters of farmers. With the intuit of characterize the young, considerating aspects like quotidian life, education, their occupation inside and out the farm, their income, genre relations and their wishes for the future, was applied a quiz to the parents and other to the young aged 1525, in the agricultural villages Amazonas and Pará, in Serra do Mel city, Rio Grande do Norte State. Were evidenced many difficulties in the access and quality of schools/education, the young

Revista Verde (Mossoró - RN - Brasil) v.1, n.1, p. 54-66 janeiro/junho de 2006

http://revista.gvaa.com.br 


\section{REVISTA VERDE DE AGROECOLOGIA E DESENVOLVIMENTO SUSTENTÁVEL 2 GRUPO VERDE DE AGRICULTURA ALTERNATIVA (GVAA)}

do not want to remain in agricultural zones, lacking income, the girls receive less exerting the same activity of the men, and the complete lack of leisure places in the villages. Agricultural zone is pointed like a good place to live, but do not offer conditions to the young remain living there.

keywords: familiar agriculture, youth, genre relations.

\section{INTRODUÇÃO}

A agricultura familiar brasileira é marcada profundamente pelas origens coloniais da economia e da sociedade, com três grandes características: a grande propriedade, as monoculturas de exportação e a escravatura. Para Almeida (1999), no Brasil, a luta pela terra iniciou praticamente durante o período colonial quando começou a aflorar a questão da reforma agrária sob a forma de reivindicação, ao lado das lutas que pregavam a abolição da escravatura.

Nos últimos anos, a agricultura familiar tem estado no centro das atenções do movimento sindical, dos pesquisadores, do governo e dos organismos internacionais. Ela aparece como sendo a base de um modelo alternativo de desenvolvimento para o meio rural capaz de reduzir a pobreza, as disparidades de renda e o uso irracional dos recursos naturais. O debate predominante em torno da agricultura familiar trata de como torná-la mais eficiente e com maior capacidade de resistência ao mercado cada vez mais concentrado. Infelizmente, muitos ainda pensam essa atividade como um setor da economia ou, no máximo, atribuindo-lhe a função social com potencial para conter o êxodo rural, responsável pelo aumento dos problemas nas cidades.

Segundo a FAO (1992), “a reforma agrária não é uma finalidade em si mesma (...) é um meio para o fortalecimento da agricultura familiar"; entendida desta forma, como um "imperativo totalmente econômico" coloca a "agricultura familiar no centro das políticas agrárias e de desenvolvimento sustentável”. O que impressiona são os números: a agricultura familiar ocupa somente $22 \%$ da área total dos estabelecimentos agropecuários e emprega quase 4 milhões de pessoas, ou seja, 59\% do pessoal ocupado no setor agropecuário. Produz $69 \%$ da mandioca, $45 \%$ do milho e $30 \%$ do leite.

Ainda ressaltando a importância da reforma agrária para o desenvolvimento da agricultura familiar, a FAO (1992) afirma: “A reforma agrária é um poderoso instrumento de desenvolvimento econômico, político e social, em contrapartida às correntes que a justificam como um programa meramente assistencialista. É fato que a reforma agrária incrementa a produção primaria, dinamiza o comercio, gera empregos diretos e indiretos, reintroduz no mercado significativa parcela da população antes excluída, democratiza o acesso a terra e aos recursos públicos, contribui para a melhoria da distribuição de renda, fortalece a agricultura familiar e suas formas mais sustentáveis de utilização dos recursos naturais".

No Brasil, a insuficiência de políticas públicas voltadas à área rural, ao fortalecimento da agricultura familiar, e a falta de incentivo/atrativo à permanência de homens/mulheres sejam jovens, adultos, crianças e idosos no campo, vem contribuindo para que a população urbana cresça a cada ano em um ritmo acelerado.

Silva (1995) considera limitadas as atividades agrícolas como geradoras de emprego e de renda no país ressaltam a crescente importância que as novas atividades agrícolas e não agrícolas vêm assumindo na manutenção do nível de ocupação no meio rural.

Neste contexto, a juventude rural é composta por 10,9 milhões de jovens. Essa

Revista Verde (Mossoró - RN - Brasil) v.1, n.1, p. 54-66 janeiro/junho de 2006

http://revista.gvaa.com.br 


\section{REVISTA VERDE DE AGROECOLOGIA E DESENVOLVIMENTO SUSTENTÁVEL 2 GRUPO VERDE DE AGRICULTURA ALTERNATIVA (GVAA)}

parcela da sociedade cada vez mais troca o campo pela cidade, este fato evidencia um problema, assim como, uma preocupação que começa a se fazer presente no meio acadêmico em relação ao futuro da juventude rural.

De acordo com dados obtidos a partir do censo demográfico de 2001, do IBGE (1994), A população do município de Serra do Mel em 2000 era de 8.237 habitantes, sendo a sua maioria $(84,62 \%)$ residente na zona rural, com uma predominância de jovens entre 0 e 29 anos.

A juventude rural do município de Serra do Mel com idade entre 14 e 29 anos, compreende ao todo, mais de dois mil jovens, representando 30,17\% do total da população. Os rapazes são a maioria deste percentual: 16,96\%. Esses dados demonstram que vem aumentando o número de homens na área rural. Por outro lado, vem diminuindo proporcionalmente a participação das moças, que corresponde a 13,21\% da população jovem (SEBRAE, 1999).

Esta tendência reflete as condições em que vive a maioria dos agricultores familiares, em especial dos jovens. A ausência de políticas governamentais que garantam o acesso a terra e aos instrumentos de apoio (crédito, tecnologia adequada, assistência técnica, capacitação, organização da produção etc.), bem como o acesso aos serviços de educação e saúde de boa qualidade e a infraestrutura comunitária de lazer, tem diminuído as perspectivas de rapazes e moças viverem no meio rural. Além disso, as dificuldades para viabilizar outras alternativas de trabalho e renda no campo (não necessariamente ligadas às atividades agrícolas) aprofundam ainda mais este quadro de falta de apoio.

Nessa realidade, os jovens rurais são as maiores vítimas porque além de não encontrarem incentivos para permanecerem no campo, são levados a desvalorizar o espaço rural e incentivados muitas vezes pela própria família a procurarem os centros urbanos, por acreditar que "está na cidade as oportunidades para a realização dos seus sonhos".

Revista Verde (Mossoró - RN - Brasil) v.1, n.1, p. 54-66 janeiro/junho de 2006

http://revista.gvaa.com.br
Essa nova realidade do campo exige também atenção daqueles envolvidos direta ou indiretamente com a educação. Contudo a falta de educação e de políticas públicas tem gerado vários problemas, entre os quais pode-se mencionar: o analfabetismo; grande número de crianças e jovens fora da escola; a carência de ensino médio rural; não valorização e formação de docentes; docentes alheios à realidade rural; abandono da escola rural; ausência de infra-estrutura adequada; carência de renovação pedagógica; currículo e calendário escolar alheios à realidade rural; escola deslocadas das necessidades e das questões do mundo rural e alheia aos interesses dos trabalhadores rurais, de seus movimentos e organizações; estimuladora do abandono do campo (QUEIROZ, 2001 ).

Para o Movimento dos Trabalhadores Rurais Sem Terra, um dos principais movimentos sociais do campo brasileiro, a conquista da terra não é o bastante, a continuidade da luta exige conhecimento para lidar com assuntos práticos. A educação de crianças, jovens e adultos tornou-se prioridade no movimento.

Tendo em vista esse cenário apresentado o trabalho propõe-se a dar uma parcela de contribuição a um tema pouco estudado no Brasil e como propõe Bezerra Neto (2000): Gostaria de lançar a polêmica do debate em torno da parcela dos jovens rurais, pois esta nova ruralidade parece criar simbologias e identidades confrontadas a partir dos aposentados (inativos) e jovens (ativos) do rural destas áreas. Os projetos de vida, em alguns casos, são diferenciados, onde o aposentado sustenta uma reprodução da família baseada numa agricultura de subsistência enquanto os jovens parecem não mais se projetar no futuro desta agricultura. Faz-se, portanto, necessário o estudo sobre a juventude rural dentro do contexto de transformação pelo qual passa a agricultura familiar, com esse intuito se realizou esse estudo nas vilas agrícolas Amazonas e Pará, no município de Serra do Mel, através da aplicação de 


\section{REVISTA VERDE DE AGROECOLOGIA E DESENVOLVIMENTO SUSTENTÁVEL 3 GRUPO VERDE DE AGRICULTURA ALTERNATIVA (GVAA)}

questionários aos pais e jovens (filhas e filhos) entre 15 e 25 anos, levando em conta aspectos de sua escolaridade, suas atividades nos lotes, suas atividades de lazer, seus anseios e perspectivas futuras.

\section{MATERIAL E MÉTODOS}

O município de Serra do Mel - região de terras produtivas encravadas entre os rios Mossoró e Assu - emergiu de um projeto de colonização iniciado em 1974 e concluído em 1982, planejado e executado pelo governo estadual, conforme o modelo dos "moshavi" (Israel), sendo o único município que resultou de uma área de assentamento de trabalhadores sem terra no estado do Rio Grande do Norte.

O projeto Serra do Mel, foi dividido em vilas comunitárias de produção (23 núcleos habitacionais, sendo 22 vilas rurais e 01 vila central), situado numa região ímpar em nível geográfico, numa área aonde o sertão chega ao litoral, prosperou rapidamente, fazendo crescer seu nível populacional. São 1.196 lotes agrícolas no espaço original do projeto de colonização. Os lotes agrícolas de Serra do Mel, quase todos com 50 hectares, foram projetados para dispor de: 15 ha para a cultura do caju (permanente), 10 ha para as culturas temporárias e 25 ha em mata nativa para reserva florestal e expansão da área de exploração agropecuária.

A autonomia política aconteceu através da lei $\mathrm{n}^{\circ}$. 803, de 13 de maio de 1998 , tendo suas terras desmembradas de Assu, Areia Branca, Carnaubais e Mossoró, tornando-se um novo município do Rio Grande do Norte (SEBRAE, 1999).

O município de Serra do Mel tem uma extensão territorial de $579 \mathrm{Km}^{2}$, equivalente a 1,09\% da superfície estadual e, conforme a divisão territorial do Brasil, pertence a Mesorregião Oeste Potiguar inserida na microrregião de Mossoró. Localizase a uma altitude média de 215 metros acima do nível do mar, situando-se numa posição geográfica determinada pelo paralelo de $05^{\circ}$
10' 12" de Latitude Sul e $37^{\circ} 01^{\prime}$ '46" de longitude Oeste, entre os vales dos rios Assu e Mossoró. O clima é semi-árido, com temperatura média anual de 27,3 C. A umidade relativa do ar média anual é de $69 \%$. A vegetação é formada, entre outras espécies, por jurema preta, mofumbo, faveleiro, marmeleiro, xiquexique e facheiro, sendo o tipo predominante à caatinga hiperxerófila, de caráter mais seco, com abundância de cactáceas, plantas de porte mais baixo e espalhadas.

O período da pesquisa compreendeu os meses de agosto a novembro do ano de 2002. A amostra total da pesquisa foi dimensionada em 74 famílias rurais, 74 filhos e 86 filhas, abrangendo 02 vilas rurais (Amazonas e Pará).

A escolha das vilas foi feita de forma aleatória entre aquelas que possuem maior número de colonos residentes. Em função disto, foram escolhidas as vilas Amazonas e Pará, por apresentarem realidades similares as demais vilas, o que beneficiaria a realização deste trabalho.

Na coleta dos dados utilizou-se a aplicação de questionários para o levantamento dos dados acerca das famílias residentes nas duas vilas pesquisadas, com questões sobre o futuro, os sonhos e as perspectivas dos filhos e das filhas dos agricultores.

A utilização do questionário se da em função do mesmo permitir a coleta de dados qualitativos e quantitativos que nortearão toda a caracterização dos entrevistados.

"É a forma de interlocução planejada que permite suscitar dos informantes respostas escritas ou verbalizada, sobre assuntos que saibam opinar ou informar, primordial para que se alcance os objetivos da pesquisa" (CHIZOTTI, 1998 citado por BEZERRA NETO, 2000).

\section{RESULTADOS E DISCUSSÃO}

Revista Verde (Mossoró - RN - Brasil) v.1, n.1, p. 54-66 janeiro/junho de 2006

http://revista.gvaa.com.br 


\section{REVISTA VERDE DE AGROECOLOGIA E DESENVOLVIMENTO SUSTENTÁVEL 4 GRUPO VERDE DE AGRICULTURA ALTERNATIVA (GVAA)}

Quando questionados filhos e filhas, quanto ao desejo de permanecer morando ou não na zona rural (vilas agrícolas), obteve-se os seguintes dados: Entre os 74 filhos entrevistados, $72,98 \%$ responderam que não desejam permanecer morando em seus lotes na zona rural. Quanto às filhas a maioria delas, $86,05 \%$ respondeu que não desejam continuar morando na zona rural (Figura 1)

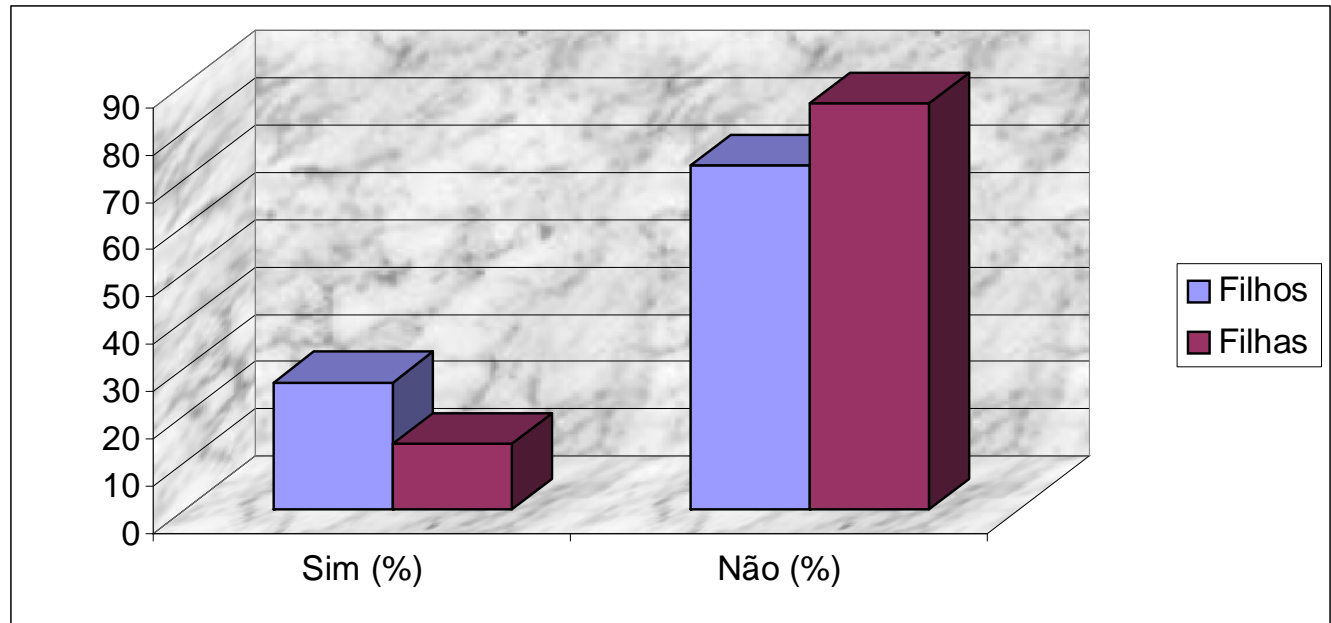

Figura 1 - Resposta dos jovens das Vilas Amazonas e Pará acerca de seu desejo de continuar residindo na zona rural do município de Serra do Mel.

No tocante aos pais, quando questionados sobre o assunto, afirmaram o seguinte: em relação aos filhos, 41,89\% deles responderam que desejam que eles permaneçam e 45,95\% afirmaram que não desejam.

Em relação às filhas, 50,0\% responderão que não desejam que suas filhas permaneçam na zona rural; 35,14\% responderam que desejam que suas filhas permaneçam na zona rural (Figura 02).

Fica evidente, de acordo com a analise dos dados, que o desejo de não permanecer na zona rural é bastante elevado entre os filhos $(72,98 \%)$ e as filhas $(86,05 \%)$ dos agricultores. Quanto aos pais, pode-se constatar que os mesmos preferem que as filhas não permaneçam na zona rural $(50,0 \%)$, superior a mesma opinião quanto aos filhos (45,95\%).

Esse dado acerca do desejo dos pais na permanência ou não dos filhos e das filhas pode influenciar na opinião dos filhos cujas respostas em relação à não permanência coincidem com a dos pais. Aliado a isso podese ter a pouca ou nenhuma remuneração delas nas atividades do lote e a não existência de atividades ditas não agrícolas que gerem renda nas vilas. 


\section{REVISTA VERDE DE AGROECOLOGIA E DESENVOLVIMENTO SUSTENTÁVEL 1 GRUPO VERDE DE AGRICULTURA ALTERNATIVA (GVAA)}

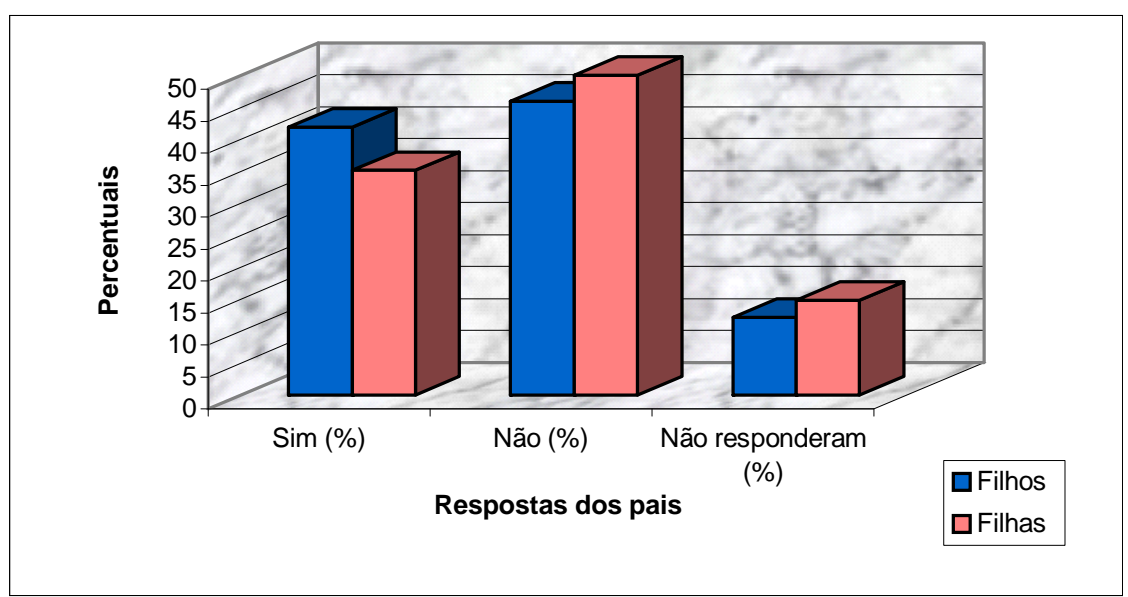

Figura 2 - Resposta dos pais das Vilas Amazonas e Pará acerca de seu desejo de que seus filhos e filhas continuem residindo na zona rural do município de Serra do Mel.

Dos filhos entrevistados 56,76\% responderam que não acreditam que terão um futuro melhor vivendo na agricultura; $41,89 \%$ responderam que acreditam que terão um futuro melhor vivendo na agricultura.

Das filhas entrevistadas $86,05 \%$ responderam que não tem expectativas de ter um futuro melhor vivendo da agricultura.
Os pais responderam que $18,92 \%$ acham que sim, seus filhos e filhas terão um futuro melhor se continuarem vivendo da agricultura, enquanto $70,27 \%$ e $10,81 \%$, acham que não e não souberam responder, respectivamente (Figura 03).

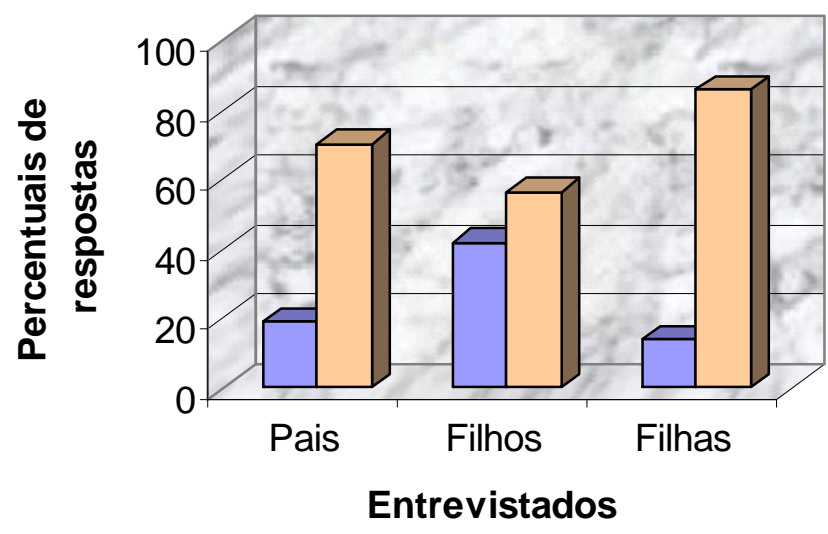

$\operatorname{Sim}(\%)$

$\square$ Não (\%)

Figura 3 - Resposta dos jovens e dos pais das Vilas Amazonas e Pará acerca de ter um futuro melhor se de continuar residindo na zona rural do município de Serra do Mel.

Pode-se observar com as respostas, que entre os filhos e filhas o maior percentual de respostas negativas, evidencia a falta de perspectiva dos jovens com as atividades rurais.
Entre as filhas, a maioria respondeu que não tem uma perspectiva de futuro melhor na zona rural, principalmente se forem depender de renda proveniente da agricultura. Esta informação reforça, segundo Abramovay (1998), a tendência do êxodo rural

Revista Verde (Mossoró - RN - Brasil) v.1, n.1, p. 54-66 janeiro/junho de 2006

http://revista.gvaa.com.br 


\section{REVISTA VERDE DE AGROECOLOGIA E DESENVOLVIMENTO SUSTENTÁVEL 2 GRUPO VERDE DE AGRICULTURA ALTERNATIVA (GVAA)}

feminino em áreas de pequena produção, nas quais a filha jovem é o elo mais frágil no minguado processo de sucessão familiar - é tão violento que já sinaliza uma desproporção masculinizante no campo. Por conta disso há um déficit de 300 mil mulheres no campo brasileiro.

Com relação ao sistema educacional no município de Serra do Mel é formado pelas redes municipal e estadual.
Existem no município 22 (vinte dois) estabelecimentos de ensino, sendo 03 (três) na zona urbana e 19 (dezenove) na zona rural. A taxa de alfabetização da população do município de Serra do Mel é de 51,90\%, segundo dados do último censo demográfico, sendo que $18,00 \%$ da população alfabetizada concentra-se na zona urbana e o restante 82,00\%, na zona rural (Tabela 1).

Tabela 01 - Índice de alfabetização da população urbana e rural do município de Serra do Mel-RN.

\begin{tabular}{lccc}
\hline \multirow{2}{*}{ POPULAÇÃO } & \multicolumn{3}{c}{ ÍNDICE DE ALFABETIZAÇÃO } \\
\cline { 2 - 4 } & TOTAL (\%) & URBANA (\%) & RURAL (\%) \\
\hline Serra do Mel & 51,90 & 18,00 & 82,00 \\
Rio Grande do Norte & 58,98 & 79,28 & 20,72 \\
\hline
\end{tabular}

Fonte: IBGE - Censo Demográfico de 1991. (IBGE, 1994).

No tocante a qualidade do ensino e a filhas $(65,11 \%)$ acham que a escola não atende sua adequação ao meio rural no qual a escola aos seus anseios (Figura 4). esta inserida, nota-se que os filhos $(64,86 \%)$ e

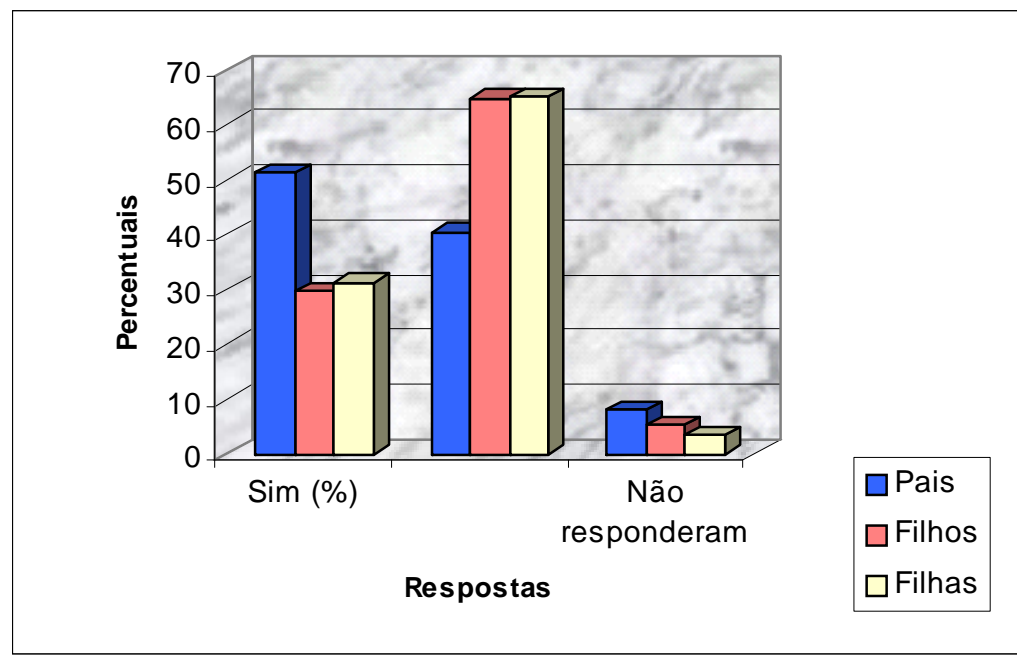

Figura 4 - Resposta dos jovens e dos pais das Vilas Amazonas e Pará acerca da qualidade do ensino nas escolas do município de Serra do Mel.

A maioria dos jovens declarou que a escola não possui professores qualificados, é desorganizada, falta mais investimento do governo, não prepara os jovens para ficar na terra e apresenta um sério problema com a falta de transporte pelo constante atraso no pagamento ocasionando desistências e reprovações.

Em relação à opinião dos pais percebe-se que possuem uma visão diferente 


\section{REVISTA VERDE DE AGROECOLOGIA E DESENVOLVIMENTO SUSTENTÁVEL 2 GRUPO VERDE DE AGRICULTURA ALTERNATIVA (GVAA)}

dos filhos, pois $51,35 \%$ acham que a escola é boa, que oferece condições adequadas de ensino aos seus filhos. Enquanto 40,54\% acham que não e $8,11 \%$ não responderam. A maioria dos pais acha que o maior problema é a falta de transporte em função do atraso no pagamento dos carros por parte da prefeitura.

Segundo dados do IBGE (1994) apesar de se ter uma população rural com percentual de $82,00 \%$ de alfabetizados, constata-se que os pais e filhos parecem ter percebido a importância que a educação possui, contudo, verifica-se que falta o ensino qualidade. Evidenciando que a escola não estabelece um vinculo sólido nem com a cidade nem com o meio rural.

Tal afirmação pode ser comprovada em função dos resultados obtidos nas Tabelas 02, 03 e 04 onde pode-se observar as principais profissões/atividades almejadas pelos jovens. Em sua maioria os jovens não almejam profissões ligadas diretamente a zona rural, ao contrário, são ocupações que se afinam mais com a zona urbana. Esse mesmo comportamento se verifica em relação aos pais quando questionados sobre o assunto.

Tabela 2 - Profissões, mais citadas, desejadas pelos pais para os filhos/filhas no futuro

\begin{tabular}{ll}
\hline \multicolumn{1}{c}{ PAIS ENTREVISTADÕ } \\
\hline Engenheiro para os filhos & \multicolumn{1}{c}{ Profissões para as filhas } \\
Professor & Professora \\
Advogado & Enfermeira \\
Médico & Advogada \\
Tenha uma profissão & Médica \\
Não Sabe & Secretária \\
& Veterinária \\
\hline Fonte: Pesquisa de & Tenha uma profissão \\
\hline
\end{tabular}

Fonte: Pesquisa de Campo - Agosto/Novembro de 2002

Tabela 03 - Respostas das profissões desejadas pelos filhos para o futuro nas vilas agrícolas Amazonas e Pará no município de Serra do Mel

\begin{tabular}{lcc}
\hline \multicolumn{1}{c}{ FILHOS ENTREVISTADOS } \\
\hline \multicolumn{1}{c}{ Profissões desejadas } & Total & $\mathbf{\%}$ \\
\hline Advogado & 07 & 9,46 \\
Professor & 05 & 6,76 \\
Engenheiro & 05 & 6,76 \\
Agricultor & 04 & 5,40 \\
Administrador & 04 & 5,40 \\
Jogador de futebol & 03 & 4,05 \\
Mecânico & 02 & 2,70 \\
Médico & 02 & 2,70 \\
Técnico em informática & 02 & 2,70 \\
Veterinário & 02 & 2,70 \\
Técnico Agrícola & 02 & 2,70 \\
Não soube responder & 19 & 25,68 \\
Outras & 07 & 9,46 \\
\hline
\end{tabular}

Fonte: Pesquisa de Campo - Agosto/Novembro de 2002

Revista Verde (Mossoró - RN - Brasil) v.1, n.1, p. 54-66 janeiro/junho de 2006

http://revista.gvaa.com.br 
Tabela 04 - Profissões desejadas pelas filhas para o futuro, nas vilas agrícolas Amazonas e Pará no município de Serra do Mel

\begin{tabular}{|c|c|c|}
\hline \multicolumn{3}{|c|}{ FILHAS ENTREVISTADAS } \\
\hline Profissões desejadas & Total & $\%$ \\
\hline Enfermeira & 16 & 18,60 \\
\hline Medica & 13 & 15,12 \\
\hline Advogada & 07 & 8,14 \\
\hline Professora & 07 & 8,14 \\
\hline Cantora & 03 & 3,49 \\
\hline Bióloga & 02 & 2,33 \\
\hline Veterinária & 02 & 2,33 \\
\hline Bioquímica & 02 & 2,33 \\
\hline Não soube responder & 23 & 26,74 \\
\hline Outras & 11 & 12,79 \\
\hline
\end{tabular}

Fonte: Pesquisa de Campo - Agosto/Novembro de 2002

A participação e a renda proveniente ou não do lote foram analisadas, pretendendose com isso demonstrar se os jovens possuem uma ocupação e se o meio rural no qual estão inseridos oferecesse renda incentivaria sua permanência.
De acordo com os dados da Figura 5 verifica-se em relação aos filhos que 47,30\% afirmaram possuir renda e 51,35\% declararam não possuírem renda.

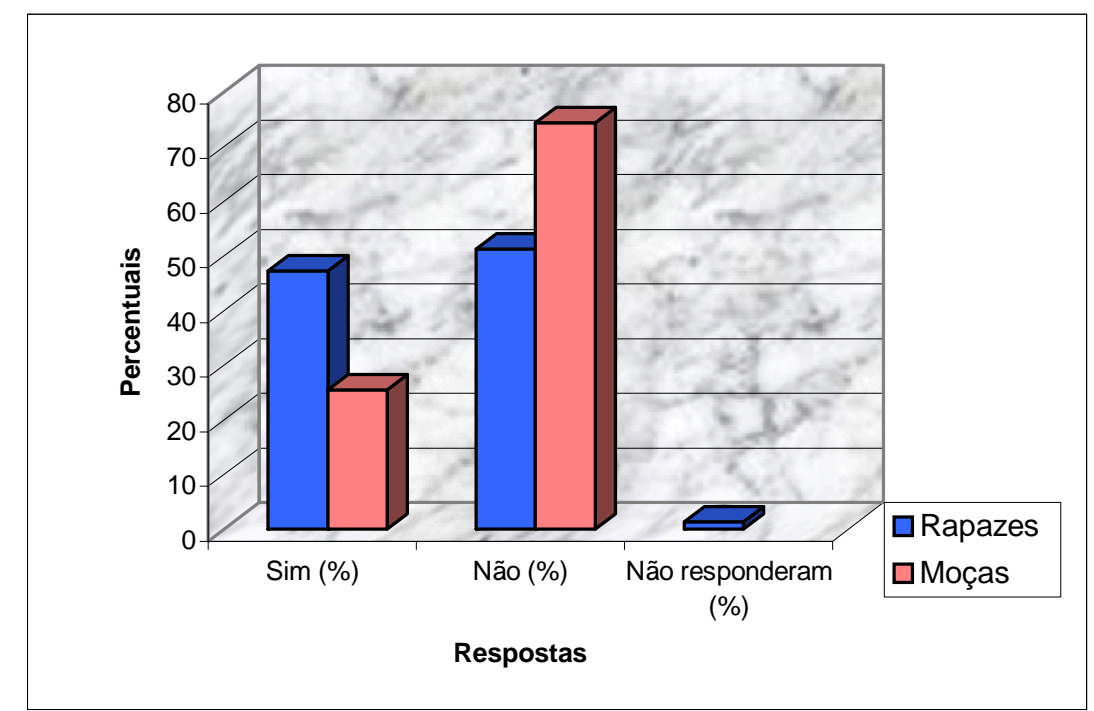

Figura 5 - Resposta dos jovens das Vilas Amazonas e Pará, acerca de sua renda na zona rural do município de Serra do Mel.

Revista Verde (Mossoró - RN - Brasil) v.1, n.1, p. 54-66 janeiro/junho de 2006 http://revista.gvaa.com.br 


\section{REVISTA VERDE DE AGROECOLOGIA E DESENVOLVIMENTO SUSTENTÁVEL 1 GRUPO VERDE DE AGRICULTURA ALTERNATIVA (GVAA)}

Na Figura 6, pode-se verificar que $86,49 \%$ dos filhos afirmaram que trabalham no lote; enquanto as filhas $50,00 \%$ delas afirmaram que trabalham e outras $50,00 \%$ afirmaram que não trabalham nas atividades do lote e sim em atividades domésticas.

Dos dados analisados, observa-se que dos filhos entrevistados $47,30 \%$ afirmaram ter renda, enquanto que $74,42 \%$ das filhas não possuem renda. Estes dados, quando comparados aos filhos e filhas que trabalham nos lotes verifica-se que mesmo apesar de $86,49 \%$ e $50,00 \%$ dos filhos e filhas, respectivamente, se ocuparem em atividades como: apanhar e descascar castanha, apanhar caju, ajudar no roçado e ajudar com as criações os jovens não possuem renda como afirmam as filhas $(74,42 \%)$ e os filhos (51,35\%).

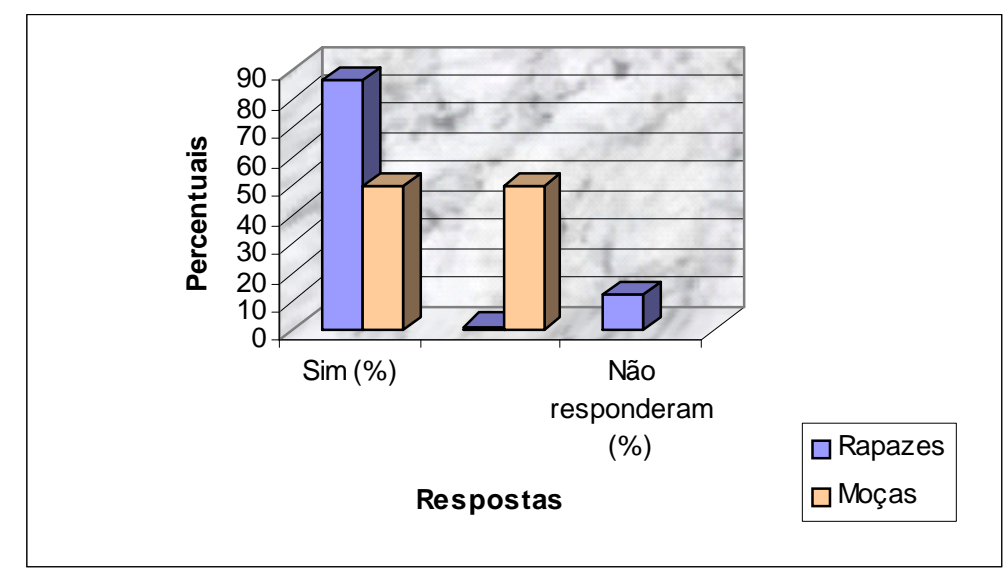

Figura 6 - Percentuais dos jovens que trabalham nos lotes nas Vilas Amazonas e Pará, na zona rural do município de Serra do Mel.

Na Figura 7, pode-se comprovar que apenas $14,28 \%$ das filhas afirmam possuir renda proveniente de atividades do lote, enquanto $43,24 \%$ dos filhos declararam possuir renda proveniente dessas atividades 


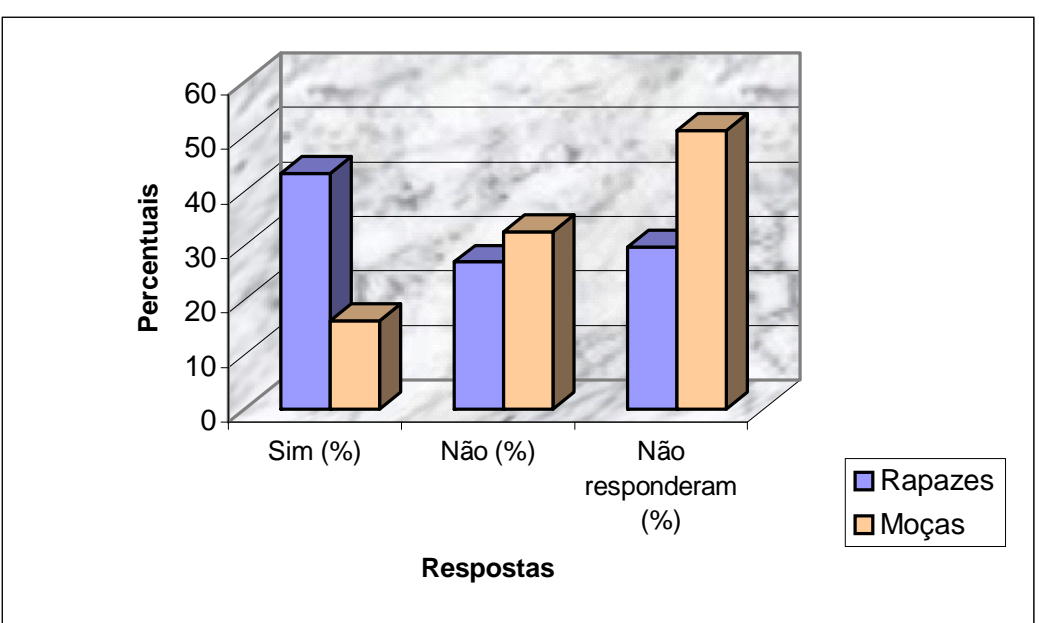

Figura 7 - Percentual de jovens das Vilas Amazonas e Pará, que possuem renda proveniente do lote na zona rural do município de Serra do Mel.

Na região em estudo de modo geral, as mulheres, as filhas e filhos ajudam nas atividades do lote. Observou-se que mesmo realizando as mesmas atividades dos filhos nos lotes as filhas possuem renda bem inferior a deles.

Na Figura 8, pode-se verificar que na opinião da maioria dos pais (86,49\%), filhos $(74,32 \%)$ e filhas $(90,70 \%)$ não existem atividades de lazer para os jovens das vilas estudadas. As respostas positivas se referem a campos de futebol.

Para os pais, filhos e filhas deveriam existir áreas de lazer, quadra de esportes, praças e atividades culturais (festas) que proporcionem um mínimo de lazer para aqueles que moram nas vilas agrícolas.

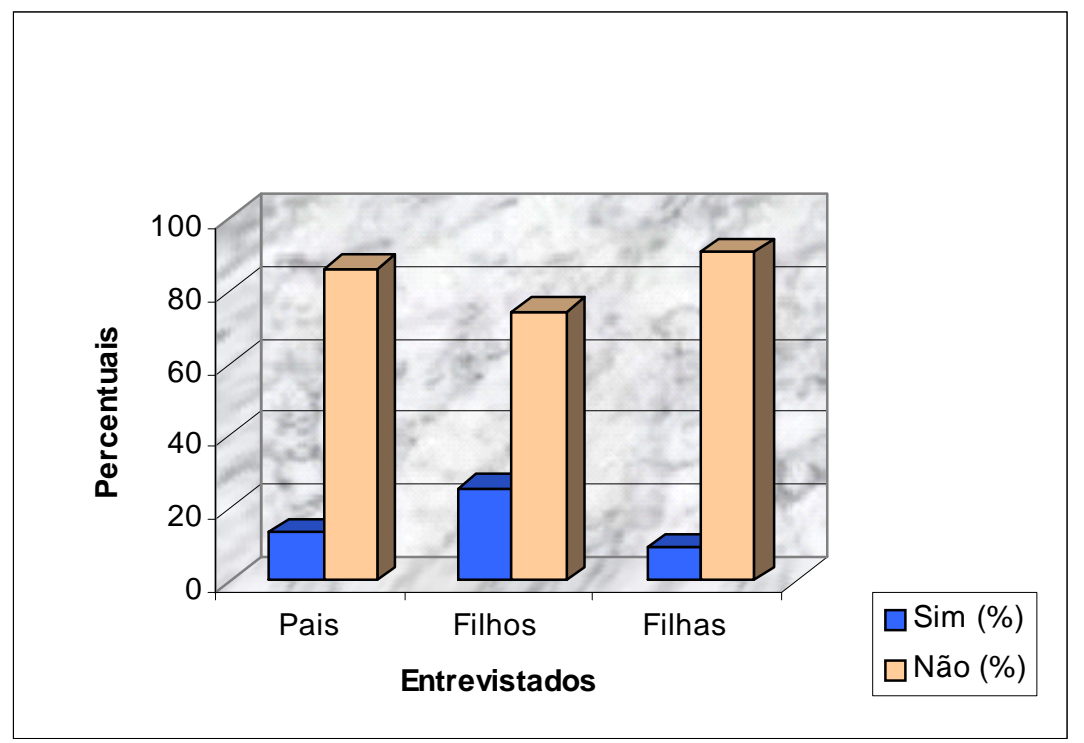

Figura 8 - Resposta dos jovens e dos pais das Vilas Amazonas e Pará, acerca da existência de atividades de lazer na zona rural do município de Serra do Mel.

Revista Verde (Mossoró - RN - Brasil) v.1, n.1, p. 54-66 janeiro/junho de 2006 http://revista.gvaa.com.br 


\section{CONCLUSÕES}

a) A maioria dos filhos (56,76\%) e filhas (86,05\% ) respondeu que não terão um futuro melhor vivendo na zona rural. Os pais (70,27\%) também compartilham dessa opinião;

b) Os jovens (filhos, $72,98 \%$ e filhas, 86,05\%), em sua maioria não desejam permanecer na zona rural;

c) Os pais preferem que as filhas não permaneçam na zona rural (50,0\%), superior a mesma opinião quanto aos filhos (45,95\%);

d) Apesar de segundo dados do IBGE, $82,00 \%$ da população da zona rural ser alfabetizada, os filhos $(64,86 \%)$ e filhas $(65,11 \%)$ acham que a escola não atende aos seus anseios, ou seja, a quantidade não determina a qualidade. Ao contrario o que se tem na escola é um ensino de pouca qualidade e que não estabelece um vinculo sólido nem com a cidade nem com a zona rural.

e) Os jovens vêem a educação como o meio dos mesmos saírem da zona rural preparados para buscarem na cidade melhores condições de vida é o que comprova as profissões que eles desejam. Em sua maioria os jovens não almejam profissões ligadas diretamente ao campo, ao contrário, são ocupações que se afinam mais com a zona urbana do que com a zona rural.

f) Nas atividades desempenhadas no lote comprova-se as relações desiguais entre filhos e filhas. Apesar de 50,00\% das filhas entrevistadas afirmarem que trabalham no lote a maioria não possui renda e as que afirmaram possuir renda oriunda do lote é bem inferior a dos filhos;

g) De acordo com a maioria das opiniões dos pais $(86,49 \%)$, filhos $(74,32 \%)$ e filhas (90,70\%), não existem atividades de lazer para os jovens das vilas estudadas;

h) Durante a realização desta pesquisa constatou-se que existem poucos trabalhos sobre o assunto, bem como, pessoas dedicadas ao estudo da realidade dos jovens rurais.

\section{REFERÊNCIAS BIBLIOGRÁFICAS}

ABRAMOVAY, R. et al. Juventude e Agricultura Familiar: Desafios dos novos padrões sucessórios. Brasília: Unesco/FAO/Incra/Epagri; 1998.101p.

ALMEIDA, J. A construção social de uma nova agricultura: tecnologia agrícola e movimentos sociais no sul do Brasil. Porto Alegre: Ed. Universidade/UFRGS, 1999.

BEZERRA NETO, P. dos S. O Novo Rural Potiguar: Os condicionantes de composição das rendas das famílias rurais no pólo de fruticultura irrigada Açu/Mossoró (RN). Mossoró: ESAM. 42p., 2000. (Monografia de Graduação).

FAO. Principais Indicadores SócioEconômicos dos Assentamentos de Reforma Agrária. FAO/PNUD Ministério da Agricultura e Reforma Agrária, Projeto BRA 87/022, Janeiro 1992.

SILVA, José Graziano da. Resistir, Resistir, Resistir: Considerações acerca do campesinato no Brasil. In: CONGRESSO BRASILEIRO DE ECONOMIA E SOCIOLOGIA RURAL, 33., 1995. Curitiba, PR. Anais... Curitiba: SOBER,1995, v.2., p.762-777.

IBGE. Censo Demográfico de 1991: Brasil. Rio de Janeiro, 1994.

QUEIROZ, J.B.P. de . Os Centros Familiares de Educação em alternância no Brasil. CADERNO VOZES - Nº 6, Nov./Dez.2001. 
REVISTA VERDE DE AGROECOLOGIA E DESENVOLVIMENTO SUSTENTÁVEL 2 GRUPO VERDE DE AGRICULTURA ALTERNATIVA (GVAA)

SEBRAE. Diagnóstico e Plano Estratégico de Desenvolvimento do Município de Serra do Mel/Rn - Natal: SEBRAE/RN, 1999.57p.

Revista Verde (Mossoró - RN - Brasil) v.1, n.1, p. 54-66 janeiro/junho de 2006 http://revista.gvaa.com.br 